deposit presented peculiarities which were difficult to explain, a red deposit was rapidly thrown down, and on microscopic examination it presented the appearance of shreds of fibrous tissue with minute fatty globules entangled in it; along with this numerous blood corpuscles were seen. The deposit was so different from anything that $I$ had previously seen that I submitted it to others for examination, and the consensus of opinion was that these shreds nere probably the débris from a renal or vesical tumour. Examination of the bladder with the cystoscope showed it to be practically normal, the only morbid condition was the appearance of the orifice of the left ureter. which was ragged and elerated and presented very much the appearance of the crater of a volcano. While observing the appearance of the ureter blood-stained material was seen to escape from it: this examination led me to suspect the presence of a tumour in the kidney, but the history of the case as given by Dr. Dunsmuir rather favoured moreable kidney leading to torsion of the renal vessels. With the assistance of Dr. D. McK. Dewar I exposed the kidney and found it to be healthy but very free and moveable; a large portion of the adipose capsule was removed and the kidney sutured to the parietes. Since the operation there has been no hæmaturia. During one of the attacks of hæmaturia, while the patient was in the "home," the blood suddenly disappeared and recurred five hours after, apparently more profusely than before. The clearing up of the urine was coincident with increase in the pain and swelling in the renal region and the reappearance of blood gave relief to the pain and swelling and a cast of the ureter was found in the urine.

(To be continued.)

\section{THE PATHOLOGY OF NEUROPATHIC KERATITIS.}

BY PERCT FLEMMING, F.R.C.S. ENG.,

ASISTANT OPHTHLLMIC SURGEON TO THE UNIVERSITY COLLEGE HOSPITAL.

HHE occurrence of corneal lesions in association with affections of the trigeminal nerve is well known, but much difference of opinion exists regarding the exact nature of the relationship between the two lesions. The various hypotheses suggested fall into two main groups. In the one the keratitis is regarded as a direct example of perverted trophic action of the nerrous system, whereas in the other such a supposed action of the nervous system is regarded as needless and the various effects are thought to be mainly due to the anæsthesia. This insensitive condition of the cornea may act in various ways. Thus foreign bodies may lodge on the cornea and, not being felt, may remain and cause irritation and ulceration. The stimulus to the reflex action of the orbicularis (blinking) being wanting the cornea will not be properly moistened, and this condition may also in part be due to arrest of actirity of the lacrymal gland. Again, owing to the sensory paralysis slight injuries (with perhaps microbic invasion from the lacrymal sac or conjunctiva) may give rise to excessire vaso-motor reaction and in this way become more extensive and the reparative processes fail to take place.

During the last year several cases of "neuropathic keratitis" hare been under my care at University College Hospital, and as each has some points of special interest I vropose to briefly record them and at the same time to review previously recorded clinical cases and post-mortem examinations and also the experimental investigations, with the object of ascertaining how far such evidence favours one or other of the previously mentioned hypotheses.

Now, in the first place, constant exposure of the eye with consequent liability to injury and dryness does not at all necessarily lead to keratitis. Everyone is familiar with cases of uld-standing Bell's paralysis in which the cornea has been exposed for years without any damage resulting. And it is quite exceptional to meet with a case of Graves's disease with an infiammation of the exposed cornea. Again, I have notes of a case of a patient who had a serere burn when a child, involving the forehead and eyelid, which prevented effectual closure of the lids, and yet after ten years there had not been the slightest sign of ulceration. Frequently associated with the fifth nerve lesion is a paralysis of other cranial nerves (oculo-motor, \&c.), and the presence of ptosis, with consequent protection, does not prevent-though it may modify-the occurrence of typical neuropathic keratitis. And in one of my cases (Case 4) the keratitis developed subsequently to the involvement of the third nerve. Mendel and Hirschberg record a case in a child in which "neuroparalytic keratitis" existed in each eye, associated on the one side with facial paralysis and a sensitive cornea, and on the other with trigeminal paralysis giving rise to an anæsthetic cornea, but with no facial paralysis, and therefore no undue exposure.

In another group of cases the cornea may be completely anæsthetic for a long time and yet no keratitis be set up. The following is a case in point.

CASE 1.-A man, aged fifty years, came to the hospital with acute facial herpes, the patches being situated at the left angle of the mouth, the left lower eyelid and adjacent side of nose, and a fourth large patch on the right ala of the nose and lower lid of same side. Both cornea were insensitive and no corneal reflex could be obtained, but both were quite sound. It was impossible to bandage both eves. and as the herpes quickly subsided the man soon returned to work; and although the cornea remained insensitive for several weeks no ulceration or inflammation occurred.

Harlan ${ }^{1}$ records a case where the insensitive cornea remained sound "for years" and Gowers mentions a similar one which had been under his observation seven years. And in another of my cases to be given in detail later, the cornea was anæsthetic for some time without being inflamed. W.J. Collins ${ }^{2}$ has recorded a case where an anæsthetic cornea became cloudy " after eight months' anæsthesia with perfect pellucidity." Further, complete removal of the Gasserian ganglion in man, with consequent anæsthesia of cornea, is not necessarily followed by keratitis.

In a third group of cases, typical neuropathic keratitis exists with a normally sensitive cornea. Mendel and Hirschberg's case (previously quoted) is a case in point. Genkin reports another in which "trophic keratitis" existed with a normally sensitive cornea. Herpetic eruptions are generally regarded as trophic lesions. Two varieties of herpes of the cornea are met with-the one complicating acute febrile herpes and characterised by small vesicles on the cornea with much irritation which quickly subsides when the vesicles burst; the other occurring with herpes zoster ophthalmicus, differing from the former by the tendency to persistence of the irritation and to implication of the deeper layers of the cornea. The following case is an example of the former variety.

CASE 2. - A woman, aged thirty years, came to the hospital on Sept. 15th with much photophobia. On both upper and lower lids of the right eye were some drying up herpetic vesicles. The lids were separated with great difficulty and then a small superficial ulcer of the cornea was observed. Three weeks later the photophobia was still marked and the ulceration had spread. Ultimately the irritation subsided and the ulcers healed. In this case there was clearly no anæsthesia of the cornea.

In considering this group of cases it must be noted that Mr. Tweedy has for long taught and described that corneal ulcers, having the same clinical characters as those which occur in connexion with grave lesions of the fifth nerve, are frequently found with a normally sensitire cornea; and he thinks that their essential neuropathic nature is shown by the ready way they respond to eficient protective treatment, by the slight vascular reaction accompanying them, and by the frequency of a history of preceding neuralgia.

Lastly, in reference to the hypothesis that an insensitive cornea is less resistant to traumatism. it must be noted that operations on insensitive corneæ-insensitive, that is, from paralysis of the fifth nerre-may do quite well; and Panas $^{\mathbf{3}}$ records an example of this where the operation was necessitated by a preceding attack of "neuroparalytic keratitis."

It seems fair to conclude from the consideration of these and similar cases that mere anæsthesia of cornea with consequent dryness and impaired raso-motor reaction cannot be regarded as the essential factor in the production of the keratitis, though there can be no doubt that anrsthesia and also want of protection do modify the course of the

1 Harlan: American Journal of the Medical Sciences, vol. cxxxiv.

2 Collins : Transactions of the Ophthalmological Society of the United Kingdom, vol. viii. and vol. ix. 
inflammation. And this conclusion is further strengthened by the fact (to be more fully emphasised later) that the keratitis is frequently preceded by iritis.

The eridence respecting the remaining hypothesisnamely, that the keratitis is the direct outcome of some perrerted trophic nervous action-must be next considered. And in the first place there is a good deal of eridence of the existence of such trophic action of the nerrous system in parts of the body other than the -yye. The acute bedsores in some spinal cases, the perforating ulcer and joint affections in tabes dorsalis, the atrophy of the phalanges and joint lesions in syringomyelia, and the atrophy of skin and bone which may follow injuries of nerves are all cases in point. The last group of cases mentioned has an important bearing $o n$ the subject immediately under consideration, for Gowers states that atrophy of skin and bone in the finger-ends after a lesion of the nerve of the arm may proceed in spite of the existence and persistence of normal sensibility. So that the retention of normal sensation in a part does not in the least militate against the view that perverted trophic action is coing on at the same time. Further, there is a good deal of evidence that the changes occurring in the condition known :as facial hemiatrophy depend on lesions of the fifth nerve, and interstitial neuritis of this nerve has been found post mortem. And it is important to note that not only has itypical neuropathic keratitis been observed in these cases but also patches of choroiditis with vitreous and lenticular -opacities, these latter being probably secondary to changes in the uvea." And, lastly, in association with severe cases of trigeminal neuralgia, trophic lesions such as a falling off of the hair and eyebrows or a whitening of them have been observed.

Thus though it may be impossible to prove clinically that neuropathic keratitis is due to a trophic lesion yet such an axplanation seems most probable. The further question then arises-viz., whether such trophic action is to be viewed as one of paralysis or as one of irritation. The clinical evidence points most strongly to the process being one of irritation. In the first place, cases of herpes are associated with neuralgic pain ; in the next, a history of preceding neuralgia is very commonly to be obtained in cases of trophic keratitis, even though the cornea be anæsthetic at the time when the keratitis supervenes; thirdly, aseptic removal of the Gasserian ganglion, with healing by first intention, is not necessarily followed by keratitis even though the eye be not protected; and finally (and perhaps most important) cases are frequently met with in which a condition of ixitis may inrecede the keratitis. As bearing on these points I will 1. elate the following cases.

CASE 3.-A man, aged forty-one years, came to the hospital on Aug. 14th, 1897. The following notes were then made: "There is complete loss of sensation in the region supplied by the left fifth nerve; there is a shallow, nonvascular ulcer involving the entire extent of the left cornea with the exception of a narrow, clear zone at the outer margin, very slight ciliary injection, no facial paralysis." The patient gave a history of having previously had violent attacks of neuralgia in the left side of the head and eye. The edges of the lids were pared and sutured and the ulcer slowly healed, the cornea becoming much clearer. Later right facial paralysis with intense right-sided neuralgia superrened. Dr. Bastian, who saw the case, regarded it as one of syphilitic meningitis.

CASE 4.- The patient was admitted to. University College Hospital under Dr. Bastian in Norember, 1897, suffering from the effects of an intracranial growth. He stated that the left upper eyelid had "dropped" in the previous September and had remained in that condition ever since. Examination of the left eye showed that there was complete ptosis, the eyeball was quite immobile, the cornea was clear with well-marked circumcorneal injection and deep anterior chamber, the iris was dull, the pupil was of medium size, reacting sluggishly to light; tension was full; and the "cornea and conjunctiva were quite anæsthetic. On the right side there was paralysis of the external rectus but no affection of the cornea or iris or fifth nerve. There was -optic neuritis in each eye. In addition to the paralysis of the left third, fourth, fifth, and sixth nerres there was paralysis of the left hypoglossal and difficulty in swallowing and in articulation. Eight days after admission a small

4 Kalt: Société de Biologie, 1889, Février 23. Strümpell : Nerreakrankheiten, p. 29 . central funnel-shaped ulcer was noted in the left cornea and there was some increase in the iritis; the eye was now kept effectually bandaged and the ulcer healed in the course of three or four weeks. The patient left the hospital a few days before he died and no post-mortem examination was obtained. The points of special interest in this case are: (1) the superrention of the keratitis in spite of the protection afforded by the presence of ptosis, though doubtless the latter modified and limited the extent of the ulceration; (2) the occurrence of a deep-seated inflammation-iritisbefore the corneal trouble ; and (3) the presence of irritatice lesions (iritis and optic neuritis) at the same time that the cornea was insensitive, indicating that the trophic action is of the nature of irritation and yet may co-exist with paralysis of the ordinary afferent nerves.

CASE 5.-This patient, a woman, was in Eniversity College Hospital under the care of Dr. Bastian. On the right side the third, fourth, and sixth nerves were paralysed and there was anæsthesia over the right forehead down to the level of the palpebral fissure. The ptosis was not complete, about the upper half of the cornea being corered. In the lower half of the cornea was a superficial ulcer and above this a nebula, the horizontal upper edge of which corresponded to the edge of the drooped upper lid. There was and had been much neuralgic pain in the region of the fifth nerve. The eye was bandaged and improved a little, but there were repeated attacks of keratitis, always accompanied by severe fifth-nerve pain. The lids were, later, pared and sutured, with the result that the ulcer healed and no recurrences have taken place in the ulceration although the pain has continued. In this case the ptosis certainly modified the extent of the nlcer, but it is important to note that mere bandaging did not arrest the ulceration and also that irritation of the fifth nerve may exist with partial anæsthesia of it.

Ferrier ${ }^{6}$ has published a somewhat similar case in which neuropathic keratitis was associated with "anæsthesia dolorosa" in the territory of the fifth nerve and he regarded the keratitis as due to irritation of the nerve. Hutchinson, too, states that the cases of herpes in which the cornea is affected are those most prone to suffer subsequently from neuralgia, and this post-herpetic neuralgia may persist for months after the vesicles have disappeared and may co-exist with complete anæsthesia of the cornea. Hence the presence of an anæsthetic cornea in any one case of keratitis does not render the assumption of irritative processes of a trophic nature going on at the same time at all unjustifiable. Ohibret ${ }^{7}$ has described cases of iritis and keratitis in which there were "tender points" over the spots of emergence of the branches of the fifth nerve-an observation familiar to most-but he especially described these cases because he found that massage applied to these nerves was quickly followed by marked improvement. I have not found, however, any confirmation of this last statement.

It has been suggested that the phenomena are due to vascular dilatation the result of stimulation of a sensory nerve; but that this is inadequate is shown by the occurrence of neuropathic keratitis with such variable condition of the sensibility of the cornea and also, that though preceding: neuralgia is common, yet at the time of supervention of the keratitis anæsthesia is often present.

A review, then, of the clinical study of these cases of keratitis leads to the conclusion that the most likely explanation of them is that ther are caused by perverted trophic action, such perversion being of the nature of irritation, the various other explanations suggested being inadequate to explain all cases.

Much experimental work has been done to elucidate the nature of the action of the fifth nerve on the nutrition of the cornea. Majendie (1822) first drew attention to the effect of section of the fifth nerve on the cornea and was followed by Bernard (1863), who showed that the effect was the more marked if the animals were young or diseased at the time. Meissner (1867) showed more or less accidentally that it mas possible to divide one portion of the nerve-the inner--with the result of inducing keratitis without anæsthesia and converselv. Snellen (1857) and others tried to show that the result so obtained were merely due to slight injuries-desiccation $\& c$. , of the cornea the direct result of the anæsthesia-and.

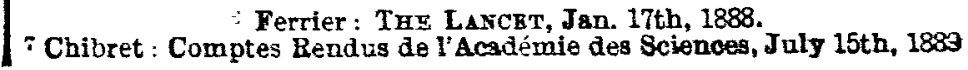


in order to explain how such slight injuries produced such severe corneal inflammation, assumed that the cornea after section of the nerve had a diminished power of resistance, an assumption which almost implies a nutritional change. Later Feuer ${ }^{8}$ and Hippel ${ }^{9}$ proved that an insensitire cornea does react in a normal way to injuries and thought that the essential factor in the causation of the keratitis was a too dry condition of the cornea. Samuel, Neissner, and especially Duval and Laborde, ${ }^{10}$ have drawn attention to the occurrence of iritis and hypopyon before the corneal lesions after section of the fifth. The latter observers-confirming an earlier suggestion of Meissner-think that they have demonstrated a bulbar nucleus concerned with these trophic functions of the fifth nerve. Laborde, ${ }^{13}$ too, has described choroidal changes developing after section of the fifth nerve exactly analogous to the changes described in some cases of facial hemiatrophy. Gaule ${ }^{12}$ describes necrotic changes in the corneal corpuscles with epithelial proliferation after division of the ophthalmic nerve, and assumes that these corpuscles are the "end organs" of the sensory nerves and degenerate in consequence of the atrophy of the nerve. On the whole the experimental work supports the hypothesis of the existence of trophic fibres in the fifth nerve (as distinct from the fibres of ordinary sensation), and bearing in mind that many of those experiments, including Meissner's, were performed in the pre-antiseptic days and contrasting them with the favourable results which follow aseptic removal of the Gasserian ganglion in man they may be taken as indicating that the essential lesion of the trophic fibres is of the nature of irritation. Some few experiments have been done with the object of ascertaining if continuous irritation of a nerve is followed by changes in the tissue, and abscesses and ulcers have been described as resulting from such imitation. But I believe these experiments are generally discredited and in any case need confirmation. In whatever way Gaule's results are to be explained his experiments are of importance as showing that a direct relation does exist between the integrity of the fifth nerve and the essential structure of the cornea.

The lesions of the fifth nerve found associated with trophic keratitis are very various, and from the point of view of the lesion being of the nature of irritation it is important to note that the nerve is as a rule only partially damaged. In one of the earliest cases the Gasserian ganglion is described as yellowish-grey; in another recorded in 1833 it is said to be enlarged and lardaceous. Alison (1836) recorded a case in which the nerve was indurated both in front and behind the ganglion. Haase (1882) found softening in the anterior part of the pons with hæmorrhage into the ganglion. Mendel's case, previously referred to, was found to be due to softening of the upper part of the pons. In a case recorded by Bernhardt there was "superficial destruction of the pons" and changes in the corpora quadrigemina. Genkin ${ }^{13}$ found in one case a gummatous tumour of the sphenoid compressing the fifth nerve. Schweinitz in a case of trophic keratitis dissected the ciliary nerves and found them to be normal. On the other hand, in a case of herpes the ophthalmic nerve was found by Wyss ${ }^{14}$ to be inflamed, the Gasserian ganglion was surrounded by blood and infiltrated with pus cells, but the nerve on the proximal side of the ganglion was healthy. The changes in the nerve were regarded as indicative of true neuritis. Hæmorrhage and degenerative change in the Gasserian ganglion have been found in other cases of ophthalmic herpes. Baudry ${ }^{15}$ relates two cases: in one the nerve was damaged by a fracture of the petrous bone and in the other the corneal changes were consecutive to a neuralgia of the fifth nerve induced by cold. In a case under the care of Mr. Tweedy the nerve and ganglion were found post mortem involved in a large sarcomatous growth.

From the above considerations it seems fair to conclude that the nutrition of the eyeball is directly dependent on the integrity and condition of certain nerve-fibres contained in the Gasserian ganglion and ophthalmic nerve, and that irritation of these fibres leads to those changes in nutrition of the cornea which are recognised as neuropathic keratitis. As to

8 Feuer: Sitzungsberichte der Kaiserlichen Academie zu Wien, 1876, 3 .

9 Hippel : Archir für Ophthalmologie, Band xxxv., 3, p. 217, 1889 10 Duval ana Laborde: Travaux de Laboratoire de Pbysiologie de la Faculté de Medecine de Paris, 1885.

It Laborde: Société de Biologie, 1889, Février 16.

12 Laborde: Société de Biologie, 1889, Février 16

13 Gankin : Archives d'Ophthalmologie i 1896, 15.

14 Wyss: Archiv der Heilkunde, Band xii. p. 284.

15 Baudry: Archires a'uphthalmologie, 1886, tome vi., p. 7C. the exact modus operandi of such irritation little can be said. The best known effect of nervous stimuli on the structure of organs is that produced by stimulating the secreting nerve of glands. Now, the nutrition of the eyeball is dependent largely on the fluids derived from the ciliary body and within the last few rears structures resembling glands have been described in the ciliary processes and those glands have been found enlarged and showing increase in their epithelium in cases of "serous iritis," a con. dition characterised by increase of aqueous humour and alteration in its composition, as evidenced by the presence of keratitis punctata. It seems possible that the trophic nerres of the eyeball may be the nerves which supply these glands and that abnormal stimulation of them may lead both to an increase in the fluid secreted and an alteration in its composition. In support of this suggestion I would recall the fact previously cited, that frequently in experimental investigations hypopyon precedes the occurrence of keratitis, and a similar sequence may be observed. clinically; and also that stimulation of the fifth nerve, as. in some cases of trigeminal neuralgia, leads to increase of tension and a deepening of the anterior chamber. Further, the facts alluded to in discussing facial hemiatrophy tend in the same direction. But at the same time it must be allowed that the connexion between the nerves and the integrity of the cornea may be more direct and intimate than this, and although such connexion has not been definitely proved, yet the occurrence of discrete herpetic vesicles on the cornea and the degeneration of the corpuscles. after section of the nerve make such a supposition quite possible.

Wimpole-street, $w$.

\section{ON THE HEART-RADIAL INTERVAL AND A HITHERTO UNKNOWN METHOD OF COMPENSATION IN AORTIC REGURGITATION.}

BY PAUL M. CHAPMAN, M.D., F.R.C.P. LOND., PHYSICIAY TO HEREFORD GENERAL INFIRMARY.

IN the Goulstonian lectures, published in THe LANoEr in March, 1894, I criticised at some little length the possibility of the abolition of the "presphygmic interval" in cases of pure and uncomplicated aortic regurgitation, and I made thefollowing statement, which I believed to be thoroughly justified on physiological grounds, and to be in accordance with my own experimental observations: "In his preliminary chapter on the "Variations of the Præsphygmic. Interval in Disease' Keyt gives as his first proposition that 'the præsphygmic interval is abnormally shortened in free aortic insufficiency,' and I think that this proposition, confirmed as it is from independent sources, is one that. should be admitted. He with a positiveness which almost. calls up antagonism, says "the testimony is ample and complete and establishes the fact beyond question." 'This. statement I have now to traverse, and, indeed, I am about to show, and by the graphic method which he considered to be incontrovertible, that the heart-radial interval may be excessively increased in pure aortic regurgitation.

In a normal heart no blood can flow from the ventricle into. the aorta until the pressure within the ventricle has risen above the aortic blood-pressure; until this time the aortic valves. must undoubtedly remain closed. The time during which the intraventricular pressure rises during systole is called the "Anspannungzeit" or (by Keyt) the "Præsphygmic Interval." Keyt says (p. 165): "When the aortic valves are permanently open the pressures in the ventricle and aorta are always in equilibrium at the beginning of systole (the two cavities being in one), whether the mean pressure be low or high. In consequence of this oneness or equilibrium of pressure the heart's impulse and aortic pulse will be synchronous." With regard to this, I always thought that the often confused ideas of blood-flow and of pulse-wave, two wholly different things, were not sufficiently differentiated in Keyt's mind. Eren an impact against a closed valve may conceivably send on a rave, though no fluid pass through the valve. Whether this is so or not in an acting heart I am not prepared to slow. It is not likely, and it is not to 